\title{
As expectativas dos imigrantes bolivianos na cidade de São Paulo: reflexões sobre a comunicação intercultural
}

The expectations of the Bolivian immigrants in the city of São Paulo: reflections on intercultural communication

Las expectativas de los inmigrantes bolivianos en la ciudad de São Paulo: reflexiones sobre la comunicación intercultural

\section{Mónica Ayala Soliz}

- Doutora em Relações Públicas pela Universidad San Martín de Pórres (USMP), Perú

- Mestreem Relações Internacionais pela Universidad Nacional Autónoma de México (Unam)

- Graduada em Administração de Empresas pela Atlantic International University (AIU), Honolulu, HI, USA

- Graduada em Relações Públicas pela Universidad Católica Boliviana (UCB)

- Gerente geral da Aquainteg SRL

- Site: http://www.dircomsocial.com/profile/MonicaAyala

- E-mail:mayalas2005@yahoo.com

(9) Fábio Radigonda Serrato

- Especialista em Gestão Estratégica em Comunicação Organizacional e Relações Públicas pela Escola de Comunicações e Artes da Universidade de São Paulo (ECA-USP)

- Especialista em Comunicação Popular e Comunitária pela Universidade Estadual de Londrina (UEL)

- Bacharel em Comunicação Social - Jornalismo pela Universidade Norte do Paraná (Unopar)

- Conta com publicações nas áreas de comunicação intercultural e comunicação e saúde.

- E-mail: fabio.serrato@gmail.com 


\section{Resumo}

Nos últimos anos houve um incremento no número de imigrantes bolivianos na cidade de São Paulo. 0 presente texto procura analisar as expectativas econômicas, sociais e legais desses imigrantes, verificar como se dá a comunicação intercultural nos relacionamentos que eles estabelecem e identificar as dificuldades e facilidades de adaptação na cidade. Utilizando técnicas quantitativa e qualitativa, as conclusões reforçam que as estratégias de comunicação intercultural podem influenciar nas expectativas dos bolivianos sobre a cidade, além de contribuir para a integração dos referidos imigrantes.

\section{PALAVRAS-CHAVE: COMUNICAÇÃO INTERCULTURAL • GLOBALIZAÇÃO •IMIGRAÇÃO • BOLIVIANOS • SÃO PAULO.}

\section{Abstract}

In recent years there has been an increase in the number of Bolivian immigrants in São Paulo. This text seeks to analyze the economic, social and legal expectations of these immigrants. It studies the intercultural communication in relationships that they establish and identifies their difficulties as well as their ease in adapting in the city. Using quantitative and qualitative techniques, the conclusions stress that the strategies of intercultural communication can influence the expectations of Bolivians in relation to the city, besides contributing to the integration of these immigrants.

\section{KEYWORDS: CINTERCULTURAL COMMUNICATION・GLOBALIZATION・IMMIGRATION・BOLIVIANS • SÃO PAULO.}

\section{Resumen}

En los últimos años hubo un incremento en el número de inmigrantes bolivianos en São Paulo. El presente texto trata de analizar las expectativas económicas, sociales y jurídicas de estos inmigrantes, verificar cómo se da la comunicación intercultural en las relaciones que se establecen e identificar las dificultades y facilidades de adaptación en la ciudad. Utilizándose técnicas cuantitativas y cualitativas, los resultados refuerzan que las estrategias de comunicación intercultural pueden influenciar en las expectativas de los bolivianos a respecto de la ciudad, además de contribuir para a la integración de estos inmigrantes. 
A comunicação intercultural, caracterizada pelo diálogo entre culturas diferentes que convivem em um mesmo espaço, ganha cada vez mais importância na sociedade contemporânea globalizada. Uma das características da globalização atual é 0 aumento do fluxo de pessoas. Lamentavelmente, esse fluxo não tem sido acompanhado de políticas que beneficiam os imigrantes em áreas relacionadas à saúde, à educação e a oportunidades de trabalho, o que os coloca em posições isoladas e negligenciadas nos diferentes destinos que escolhem para continuar suas vidas fora do país de origem.

O fenômeno migratório pressupõe cada vez mais a presença do multiculturalismo e da interculturalidade entre pessoas de culturas distintas em um mesmo país. Como realidade multidimensional e complexa, a globalização estabelece padrões que, ao mesmo tempo, valorizam e renegam diferenças e similaridades. Assim, imigrantes e comunidades locais do país convivem em certa interdependência que envolve convergências e contradições relacionadas às práticas da comunicação e da cultura.

Na cidade de São Paulo, houve nos últimos anos forte incremento de imigração da Bolívia. Segundo o Ministério da Justiça (Brasil, 2011), em 2010 havia 961 mil estrangeiros vivendo regularmente no país, número que aumentou para 1,466 milhão em 2011. 0 Censo de 2010 indica que os bolivianos compõem a segunda maior colônia de estrangeiros em São Paulo, ficando atrás apenas dos portugueses. Conforme os dados oficiais, o número de cidadãos da Bolívia que se mudaram para a capital paulista aumentou 173\% entre 2000 e 2010, subindo de 6.578 para 17.960 (Pereira, 2013). Considerando estimativas de imigrantes indocumentados, o número é bem maior. 0 Centro de Apoio ao Migrante estima haver 250 mil bolivianos na cidade (Moreira, 2011). Já o Consulado da Bolívia em São Paulo defende que essa população é de 350 mil pessoas (Burgarelli; Toledo, 2013). Portanto, além dos documentados, existe uma população flutuante de indocumentados que não se pode ignorar.

A importância de abordar o tema da comunicação intercultural está no fato de se considerá-la um veículo de interconexão entre os protagonistas de um contexto diverso, coincidente em objetivos ou características circunstanciais. Isso significa que, em um determinado momento, a comunicação constitui para o imigrante o único meio de acesso aos conteúdos sociais de uma comunidade desconhecida.

O presente texto busca analisar as expectativas de bolivianos residentes em São Paulo frente às condições econômicas, sociais e legais; verificar a influência da comunicação intercultural sobre essas expectativas; e identificar as dificuldades e facilidades de adaptação dos bolivianos na cidade de São Paulo. Foram utilizadas técnicas qualitativa e quantitativa para obter os dados necessários.

\section{COMUNICAÇÃO INTERCULTURAL E ACULTURAÇÃO}

Os bolivianos que se mudam para São Paulo têm que lidar com o diverso, o diferente: a cultura brasileira. Geert Hofstede (1997, p. 19) define cultura como "a programação coletiva da mente que distingue os membros de um grupo ou categoria de pessoas em face a outro." De acordo com o mesmo autor, a cultura é adquirida e deve ser distinguida da natureza humana (que é herdada e universal a todos os seres humanos), bem como da personalidade (a soma do que é herdado e do que é aprendido). Para Hofstede (1997), as diferenças culturais se manifestam por meio de símbolos, heróis, rituais e valores. Esses quatro elementos constituem diversos níveis de cultura, sendo um deles o nacional, que pode conter língua, sistema educacional, sistema político, produtos, serviços, entre outras características comuns aos membros de determinada nação. 
A interação entre pessoas de diferentes culturas nacionais resulta em conflitos sociais e psicológicos, mesmo que involuntários. A maioria dos estudos sobre o tema fundamenta-se na teoria da curva em $U$, descrita inicialmente por Jens Lysgaard (Black e Mendenhall, 1991, apud González; Oliveira, 2011, s. p.) e representada na Figura 1.

Figura 1

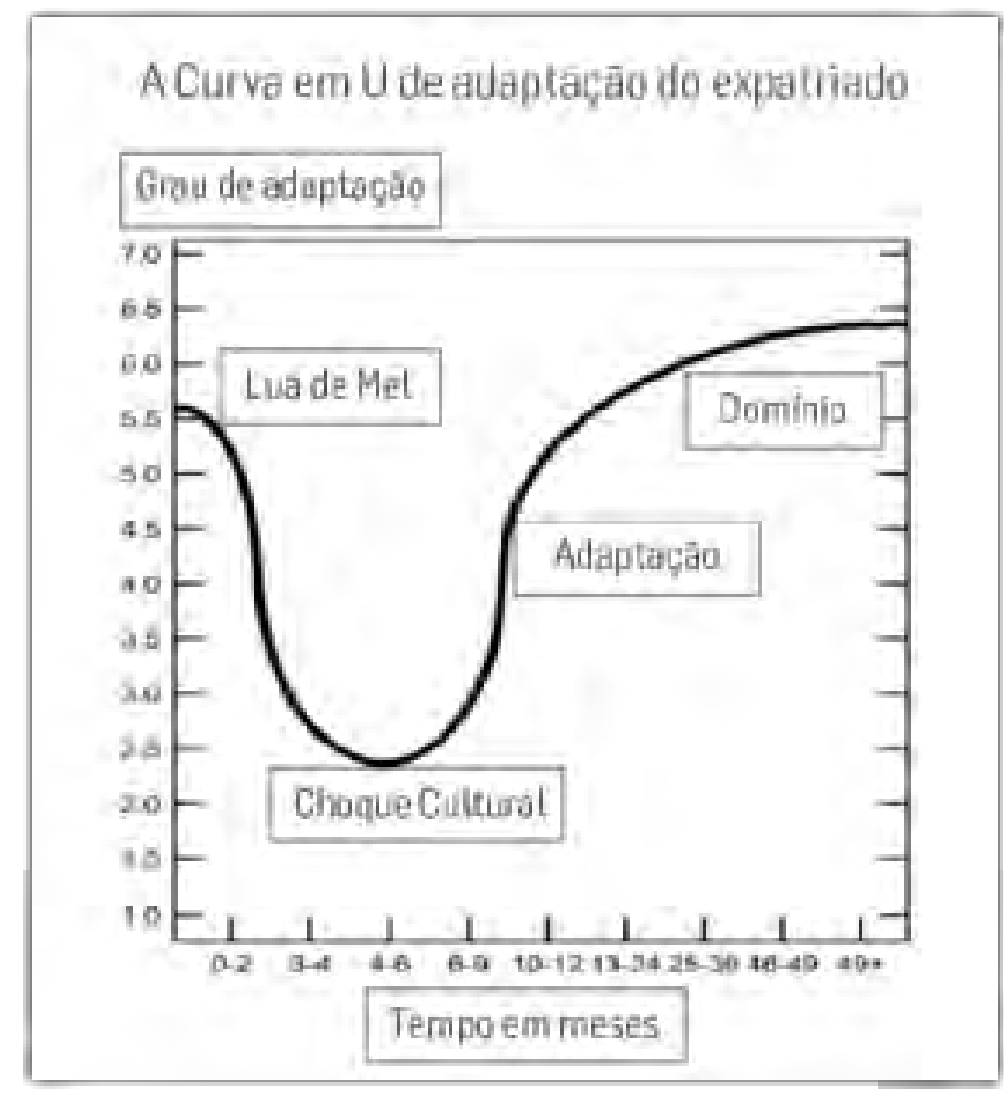

Fonte: Black; Mendenhall (1991, apud González;

Oliveira, 2011, s. p.).

De acordo com essa teoria, a primeira fase por que passa o estrangeiro em outro país é a de um período geralmente curto de euforia, pautado pela emoção do novo e pelas expectativas. Aliciados por empregadores que fazem falsas promessas, muitos bolivianos vêm ao Brasil com a expectativa de que este é o país do futebol, do carnaval, dos negros e que as pessoas são acolhedoras (Silva, 1997).

Quando o imigrante começa a vida no novo ambiente, quase sempre passa pelo choque cultural, um estado de ansiedade e stress de quem vive em um ambiente não familiar, caracterizando a segunda fase da teoria. No caso dos imigrantes bolivianos, além da exploração no trabalho, o choque cultural acontece por vários outros motivos. Cardozo (2013) enfatiza a dificuldade com o idioma português, e isso tem uma ampla dimensão devido ao fato de que a língua é um acúmulo de significados que se aprende por um processo de educação em diversos cenários, como casa, escola, trabalho, entre outros.

A terceira fase do gráfico em U é a de aculturação, na qual o imigrante aprendeu parcialmente a vivenciar as novas condições de vida, adotou alguns valores locais e adquiriu confiança em si próprio. Hofstede (1997, p. 247) reforça a importância do idioma local nesse processo quando afirma que, "quando não se conhece o idioma de um país, perdem-se numerosas sutilezas de uma cultura e vemo-nos obrigados a permanecer como observadores externos". No caso dos imigrantes bolivianos, suas raízes (quéchua ou aymaras) devem ser consideradas, visto que alguns dos bolivianos que se mudam para o Brasil têm origem indígena. Isso pressupõe que já passaram por uma migração prévia do campo para alguma cidade da Bolívia e aprenderam a viver em uma 
cidade grande, mas sua visão de mundo não mudou completamente. Seus valores culturais seguem conservando costumes e usos anteriores, e quando voltam a migrar, desta vez em um contexto mais distante, levam essa carga de significados.

A quarta e última fase, segundo Hofstede (1997, p. 242),

constitui 0 estado de estabilidade mental que finalmente se alcança. Os sentimentos podem permanecer negativos em comparação com a cultura de origem (...), por exemplo, se o visitante se sente ainda um estranho e discriminado. Mas pode sentirse igualmente tão bem como antes (...) e, neste caso, pode-se considerar que o visitante conseguiu uma adaptação bicultural, ou pode mesmo sentir-se melhor (....). Neste último caso, adaptou-se totalmente ao modo de vida dos seus anfitriões, tornando-se 'mais romano que os romanos'.

A adaptação do imigrante também é influenciada por leis brasileiras e acordos internacionais, que contribuem para a relação de multiculturalismo ou interculturalidade entre os imigrantes bolivianos e a população local de São Paulo. Nesse sentido, se faz importante o conhecimento de que o Brasil formaliza a garantia de o imigrante estudar, utilizar o Sistema Único de Saúde (SUS) - nos dois casos, independentemente de documentação - e trabalhar (desde que atenda determinadas exigências).

Outros aspectos que devem ser considerados no que diz respeito à adaptação de imigrantes bolivianos em São Paulo são os sistemas culturais propostos por Ribeiro (1988): adaptativo, associativo e ideológico.

0 sistema adaptativo compreende o conjunto de práticas através das quais uma sociedade atua sobre a natureza no esforço de prover sua subsistência e reproduzir o conjunto de bens e equipamentos de que dispõe. 0 sistema associativo compreende o complexo de normas e instituições que permite organizar a vida social, disciplinar o convívio humano, regular as relações de trabalho e reger a vida política. Finalmente, o sistema ideológico é representado pelos corpos de saber, de crenças, de valores gerados nos esforços adaptativo e associativo (Ribeiro, 1988, p. 31).

No dia a dia desses imigrantes, a interpretação e o reconhecimento dos três sistemas culturais se dão pela "subjetividade social". 0 termo, de acordo com Zemelman, "é um plano da realidade social em que se articulam a memória, a cultura, a consciência, a vontade e a utopia" (Carrillo; Azocar, 2010, s. p.).

A memória dos povos é importante porque thes dá significado e sentido de vida. No entanto, em algum momento o imigrante muda de sistema social e de significados culturais, fazendo com que a memória social não tenha eco no seu novo entorno. Essa situação pode provocar um isolamento do indivíduo por temores sociais como a rejeição e a discriminação, mas, por outro lado, em um sistema ideal de canais de comunicação e administração de mecanismos de inserção para os imigrantes, os indivíduos poderiam vivenciar uma transição positiva que permitisse conservar sua identidade sem perder a oportunidade de mudança em um novo contexto.

Finalmente, a comunicação intercultural tem papel fundamental em todo o processo de aculturação e adaptação, perpassando as questões culturais e legais apontadas anteriormente. Quando falamos de comunicação intercultural, duas definições são importantes neste estudo. Utilizamos o enfoque proposto por Maria Aparecida Ferrari (2011, p. 174), ao afirmar que

a comunicação entre os diferentes que habitam o mesmo espaço e ao mesmo tempo se dá pela necessidade do estabelecimento de uma base comunicacional comum, a partir de sua mútua compreensão a respeito do que, naquele determinado contexto, deve ser o centro da comunicação. 
R. Vila Baños (2005, p. 47) completa e conceitua a comunicação intercultural como a

comunicação interpessoal na qual intervêm pessoas com referentes culturais suficientemente diferentes para que sejam autopercebidos, tendo que superar algumas barreiras pessoais e/ou contextuais para se chegar à comunicação efetiva (tradução nossa).

Por sua vez, Daniel Mato (2012) defende que os atores sociais coletivos e institucionais geralmente são heterogêneos, competem e negociam formulações de significado entre si e dentro de si, com diferenças que não impedem a atuação conjunta. É o que acontece potencialmente com os bolivianos que imigram para o Brasil. Assim, no processo de comunicação entre as organizações brasileiras e os imigrantes bolivianos são frequentes as possibilidades de ocorrer um "mal-entendido cultural". 0 termo, de acordo com Paulo Finuras (2007, p. 172), é considerado

um conflito de comunicação (aber to ou latente), provocado pelo facto de os interlocutores serem oriundos de culturas diferentes e, consequentemente, terem diferentes valores, hábitos e códigos de conduta, enfim, serem portadoras de diferentes esquemas ou softwares mentais coletivos e diferentes escalas de valores individuais.

Na realidade dos bolivianos que vivem em São Paulo, o conflito cultural pode acontecer, por exemplo, na interpretação sobre as leis trabalhistas, as exigências para solicitar/renovar o visto, o direito à educação, os costumes e conceitos relacionados à saúde.

\section{PESQUISA COM IMIGRANTES BOLIVIANOS}

Diante do contexto até aqui apresentado, foi realizada pesquisa de caráter exploratório e empírico com a utilização de técnicas quantitativa e qualitativa, mediante entrevista individual em profundidade e aplicação de questionário. A entrevista foi realizada com Carmelo Muñoz Cardoso, presidente da Associação de Residentes Bolivianos (ADRB). Fundada em 1969, a ADRB tem como objetivos prestar apoio jurídico (principalmente em relação à documentação pessoal), incentivar o esporte, oferecer atendimento odontológico e médico.

Para a aplicação do questionário, o universo considerado para a pesquisa foram os imigrantes bolivianos residentes na cidade de São Paulo. A amostragem envolveu critérios como idade (a partir de 18 anos), além de ser usuário da ADRB, participar de atividades da comunidade boliviana em São Paulo ou frequentar a Praça Kantuta. A praça é conhecida como um pedaço da Bolívia na capital paulista. Administrada pela Associação Gastronômica Cultural e Folclórica Boliviana Padre Bento (AGCFBPB), recebe duas mil pessoas a cada domingo, sendo 90\% delas bolivianas nativas ou descendentes (Brasil-Bolívia, s. d.). A aplicação resultou em cem questionários com respostas válidas, sendo que a maior parte dos questionários foi aplicada na referida Praça.

0 roteiro da entrevista em profundidade e o questionário foram formulados com base nas seguintes variáveis: idioma/ comunicação, acesso à educação e à saúde, convivência grupal, expectativas sobre a cidade de São Paulo/o Brasil, adaptação, informações sobre direitos e perspectivas de vida na cidade. Importanteressaltar a escolha das temáticas saúde e educação, visto que são direitos básicos de todos que estão no Brasil, sejam brasileiros, haitianos, bolivianos ou pessoas de outra nacionalidade. 


\section{RESULTADOS OBTIDOS E ANÁLISE}

"Expulsos" pelas difíceis condições econômicas do país de origem, com a metade da população vivendo abaixo da linha de pobreza e o crescente aumento da distância entre ricos e pobres (Indexmundi, s. d; Lage e Roldão, 2012), os imigrantes bolivianos vêm à capital paulista com a expectativa de trabalhar e ganhar dinheiro. A informação vai ao encontro da afirmação de Sidney Antônio da Silva (2012), que cita esses motivos como característicos da imigração de bolivianos ao Brasil a partir da década de 80.

A pesquisa apontou que a expectativa dos bolivianos na cidade de São Paulo é alcançada quanto ao objetivo de trabalho. Quase todos os entrevistados estão "empregados", sendo que as oportunidades de trabalho, as condições econômicas e a possibilidade de guardar dinheiro são os motivos mais citados para incentivar um familiar ou amigo boliviano a imigrar para São Paulo. Silva (2012) relata que ainda hoje o setor de costura é o que "emprega" a maioria dos bolivianos, e que muitas vezes o regime de trabalho é análogo à escravidão. Este estudo confirma essas características. Como consequência, a maioria quer abrir o próprio negócio.

No que diz respeito à região de moradia, parte dos entrevistados vive em bairros onde se concentram as oficinas de confecção e espaços de convivência e identificação da comunidade, como Bom Retiro, Brás e Pari. Por outro lado, também se constatou, conforme indica o Censo de 2010 (Burgarelli; Toledo, 2013), a expansão desses residentes para áreas periféricas da Zona Leste e da Zona Norte da cidade. 0 censo justifica essa expansão pela busca por melhor salário e menor gasto com aluguel.

Os imigrantes bolivianos convivem principalmente em seu grupo de origem. Entre os casados, majoritariamente, o cônjuge é boliviano; no trabalho, os respondentes afirmam se relacionar principalmente com pessoas da mesma nacionalidade. No entanto, eles ressaltam a relação com os brasileiros no dia a dia e as amizades que fizeram no Brasil entre os três fatores que mais gostam em São Paulo. Em relação ao que é mais difícil na cidade, são vários os problemas, depois das condições de trabalho na cidade, como o idioma, a dificuldade de conseguir documentação pessoal, o atendimento médico e o fato de ser imigrante boliviano.

Quase a totalidade dos entrevistados afirmou que conhece um compatriota que passou por alguma situação de discriminação ou violência, seja 'ter sido vítima' de assalto/roubo na rua ou em casa, ser mal atendido em uma unidade de saúde ou os filhos serem maltratados na escola. Em relação ao sistema público de saúde, embora o atendimento médico tenha recebido críticas negativas, é considerado pelos respondentes melhor que na Bolívia.

0 não-domínio do idioma português aparece como uma importante barreira cultural que dificulta a vida desses imigrantes no Brasil. Segundo Hofstede (1997, p. 247), as palavras "são veículos de transferência de cultura". 0 idioma comum também é a essência para a realização da comunicação intercultural, estabelecendo uma base comunicacional comum "entre os diferentes que habitam o mesmo espaço" (Ferrari, 2011, p. 174). É por meio dele que se estabelece o diálogo e se evita o mal entendido cultural (Finuras, 2007).

A pesquisa mostra ainda que a cultura brasileira tolera determinados comportamentos e a ocupação de espaços específicos por parte desses imigrantes. Porém 'tolerar' não é o mesmo que 'integrar'. Os bolivianos residentes na cidade de São Paulo vivem em guetos físicos e simbólicos, constituindo uma relação de multiculturalismo: um ambiente em que várias culturas estão expostas, mas não se integram, apenas se suportam. Essas características são opostas às da interculturalidade, em que o relacionamento e o diálogo fazem com que as culturas fiquem mais próximas e haja respeito e integração entre os diferentes. 
Para a comunicação entre povos de diferentes culturas, Miquel Rodrigo Alsina (1997) e Hofstede (1997) ressaltam a importância da competência intercultural, seja por parte de quem migra, seja de profissionais do país que recebe os imigrantes. Os dados desta pesquisa mostram que os órgãos do estado brasileiro estão despreparados para criar e manter relacionamento com o público de imigrantes bolivianos, muitas vezes dificultando ou impedindo a integração desses residentes, como no caso das escolas e dos serviços de saúde.

0 relacionamento ideal com os imigrantes bolivianos deveria ter como base a comunicação intercultural, com integração e diálogo entre as culturas e o rompimento do multiculturalismo. Para isso, Rodrigo Alsina (1997) defende o desenvolvimento de 'dispositivos comunicativos interculturais', destacando-se a tomada de consciência das próprias características culturais e dos próprios processos comunicativos, o conhecimento da outra cultura e seus processos de comunicação, o idioma e a comunicação não-verbal comuns, a metacomunicação, a compreensão e experimentação dos sentimentos alheios a partir dos referentes culturais do outro e, finalmente, disposição para aprender e para romper as barreiras culturais. Como afirma Rodrigo Alsina (2001), por mais difícil que seja a comunicação intercultural, atualmente ela é inevitável.

\section{CONSIDERAÇÕES FINAIS}

O principal motivo pelo qual os bolivianos se mudam para São Paulo tem origem no nível econômico, pois eles querem trabalhar e guardar dinheiro. Em geral, seu primeiro trabalho está ligado à indústria de confecção de roupas e enfrentando um regime de trabalho análogo à escravidão. Por isso, há também a expectativa de abrir o próprio negócio em um momento posterior. A maior parte dos bolivianos quer ficar no Brasil por tempo determinado, até conseguir guardar algum dinheiro que seja suficiente para voltar para a Bolivia e instalar-se em boas condições financeiras.

O idioma é uma barreira considerável na adaptação ao país e ao trabalho, pois quase a totalidade dos respondentes nunca estudou formalmente o idioma português o que causa dificuldade para se comunicar nessa língua. Também é evidente que a discriminação e a violência física que sofrem por parte dos brasileiros prejudicam a adaptação. Outro aspecto fundamental é a indocumentação que se desdobra em várias consequências. Essa condição impede ou aos menos gera muitas dificuldades para que os residentes bolivianos em São Paulo consigam oportunidades de trabalho em outras áreas e se relacionem profissionalmente com pessoas que não sejam da mesma nacionalidade, visto que nas fábricas de costura há predominância de trabalhadores bolivianos. A indocumentação dificulta, ainda, o acesso aos direitos constitucionais de estudar e utilizar 0 Serviço Único de Saúde (SUS), dificuldades que existem por receio dos imigrantes ou pelas barreiras paradoxalmente criadas pelas próprias organizações brasileiras.

Uma das poucas facilidades de adaptação é a convivência com outros bolivianos, muitas vezes familiares, que são mesmo a principal fonte de informação sobre direitos e deveres. Também contribuem para a adaptação a utilização de espaços de identificação da comunidade, como a Praça Kantuta, e algumas relações com os brasileiros no dia a dia, tidas como um dos aspectos que mais gostam na cidade. Porém, mesmo em princípio favorecendo a adaptação, esses fatores acabam por converterse em dificuldades: em casa, no trabalho e nos poucos momentos e espaços de lazer, a convivência é majoritariamente entre os compatriotas bolivianos. 
Convivendo com os brasileiros em uma realidade multicultural, em que as culturas nacionais se toleram - já que uma é obrigada a se relacionar minimamente com a outra-, mas sem integração a comunicação intercultural praticamente inexiste, o que mais uma vez dificulta o processo de aculturação desses imigrantes. Somente a partir do momento em que houver uma "comunicação interpessoal na qual intervêm pessoas com referentes culturais suficientemente diferentes para que sejam autopercebidos, tendo que superar algumas barreiras pessoais e/ou contextuais para se chegar à comunicação efetiva" (Baños, 2005, p. 47), ou seja, uma comunicação intercultural efetiva, é que as relações entre culturas diferentes poderão se dar plenamente a ponto de estabelecerem uma relação intercultural. Assim, sem comunicação intercultural não há interculturalidade, integração e interação entre as culturas.

Para que os bolivianos que migram para São Paulo se integrem à cultura brasileira, são necessárias estratégias de comunicação intercultural que

- Gerem conhecimento sobre as possibilidades e exigências para residência no Brasil (muitas vezes a principal dificuldade para conseguir a residência temporária poderia ser suprida ao se chegar ao país com um documento de antecedentes penais da Bolívia);

- $\quad$ Comuniquem sobre as leis trabalhistas locais;

- Comuniquem sobre o direito constitucional de estudar e utilizar o Sistema Único de Saúde (SUS), independentemente da documentação;

- $\quad$ Propiciem conhecimentos do idioma português;

- Propiciem atendimento com funcionários aptos a se comunicarem interculturalmente, ao menos nos setores do serviço público que lidam com imigrantes no dia a dia.

Intensificando, dessa forma, o relacionamento com as organizações e a cultura brasileira e usufruindo dos direitos garantidos pela Constituição, os referidos imigrantes teriam mais expectativas e perspectivas no Brasil. Conclui-se, então, que a comunicação intercultural influencia diretamente nas expectativas dos imigrantes bolivianos em São Paulo.

Nessa perspectiva, a comunicação, seja esta direta ou intercultural, requer mecanismos institucionais que promovam a informação em dos âmbitos:

- $\quad 0$ âmbito institucional/legal brasileiro, que, como foi visto ao longo da pesquisa, contém benefícios educativos e também na área de saúde para os imigrantes. No entanto, o processo de acesso a eles é pouco difundido e conhecido pela comunidade de imigrantes beneficiada.

- $\quad 0$ âmbito de representação /consulados presentes no Brasil, já que um dos mandatos dos consulados, consiste em apoiar e defender os direitos dos imigrantes do país que representam. Os consulados deveriam, em conjunto com 0 governo brasileiro, gerar mecanismos interinstitucionais que difundam esses benefícios às populações imigrantes, que por medo se retraem na informalidade. 
Considerando a realidade multicultural da atualidade em que, de um lado, estão os bolivianos em condição de regime de trabalho escravo e, de outro, as organizações públicas brasileiras que não cumprem o que a legislação garante, cabe ao estado brasileiro a iniciativa e a obrigação de promover a competência e a capacitação intercultural entre as organizações e os imigrantes.

\section{REFERÊNCIAS}

BAÑOS, R. Vila La competencia comunicativa intercultural: un estudio en el primer ciclo de la ESO. 2005. $669 \mathrm{fl}$. Tese (Doutorado em Pedagogia) - Faculdade de Pedagogia, Universidade de Barcelona, Barcelona, 2005. Disponível em: <http://tdx. cat/bitstream/handle/10803/2345/2.CAP_2.pdf? sequence=6>. Acesso em: 10 ago. 2014.

BLACK, J. Stewart; MENDENHALL, Mark. The U-curve adjustment hypothesis revisited: a review and theoretical framework. Journal of International Business Studies, v. 22, n. 2, p. 225-247, 1991.

BRASIL. Ministério da Justiça. Economia brasileira atrai estrangeiros e imigração aumenta 50\% em seis meses. Portal Brasil, 01 jan. 2011. Disponível em: <http://www.brasil.gov.br/noticias/arquivos/2011/11/10/economia-brasileira-atrai-estrangeiros-eimigracao-aumenta-50-em-seis-meses>. Acesso em: 14 ago. 2014.

BRASIL-BOLÍVIA. Kantuta é um pedaço da Bolívia na capital paulista. São Paulo: Brasil Bolívia, s. d. Disponível em: <http://www. brasilbolivia.com.br/praca_kantuta_br.htm>. Acesso em: 10 ago. 2014.

BURGARELLI, Rodrigo; TOLEDO, José Roberto de. Pela 1a vez, bolivianos superam japoneses e italianos na capital. O Estado de S. Paulo, 05 maio 2013. Disponível em: <http://www.estadao.com.br/noticias/impresso,pela-1-vez-bolivianos-superamjaponeses-e-italianos-na-capital-,1028530,0.htm>. Acesso em: 13 ago. 2014.

CARDOZO, Carmelo Muñoz. Associação de Residentes Bolivianos. São Paulo, 10 maio 2013. Entrevista concedida a F. R. Serrato, para a realização da monografia.

CARRILLO, Afonso Torres; AZOCAR, Juan Carlos Torres. Subjetividad y sujetos sociales en la obra de Hugo Zemelman. Shvoong. com, 23 jan. 2010. Disponível em: <http://es.shvoong.com/social-sciences/education/1967247-subjetividad-sujetos-socialesen-la/\#ixzz2drwFKwDM>. Acesso em: 12 ago. 2014.

FERRARI, Maria Aparecida. Contexto global e latino-americano da comunicação e relações públicas. In: GRUNIG, James; FERRARI, Maria Aparecida; FRANÇA, Fábio. Relações públicas: teoria, contexto e relacionamentos. 2. ed. São Caetano do Sul, SP: Difusão Editora, 2011. p.131-246.

FINURAS, Paulo. Gestão intercultural: pessoas e carreiras na era da globalização. 2. ed. Lisboa: Edições Sílabo, 2007.

GONZÁLEZ, Juan Miguel; OLIVEIRA, José Arimatés de. Os efeitos da expatriação sobre a identidade: estudo de caso. Cad. Ebape. br, Rio de Janeiro, v. 9, n. 4, dez. 2011. Disponível em: <http://bibliotecadigital.fgv.br/ ojs/index.php/cadernosebape/article/ viewFile/5237/3971>. Acesso em 14 ago. 2014. 
HOFSTEDE, Geert. Culturas e organizações. Lisboa: Editora Sílabo, 1997.

INDEXMUNDI. Dados históricos gráficos. Indexmundi, 2012. Disponível em: <http://www.indexmundi.com/g/g. aspx?v=69\&c=bl\&l=pt>. Acesso em: 11 ago. 2013.

LAGE, Janaina; ROLDÃO, Rafael. ONU: mais de 1/4 da população pobre da América Latina vive no Brasil. O Globo, Rio de Janeiro, 21 ago. 2012. Disponível em: <http://oglobo.globo.com/mundo/onu-mais-de-14-da-populacao-pobre-da-america-latina-vive-nobrasil-5851772>. Acesso em: 12 ago. 2014.

MATO, Daniel. Heterogeneidade social e institucional, interculturalidade e comunicação intercultural. Matrizes, Universidade de São Paulo, v. 6, n. 1-2, p. 59-93, jun. 2012.

MOREIRA, Marli Imigrantes fazem manifesto em São Paulo pelo direito a voto. Ebc.com.br, São Paulo, 04 dez. 2011. Disponível em:<http://agenciabrasil.ebc.com.br/noticia/2011-12-04/imigrantes-fazem-manifesto-em-sao-paulo-pelo-direito-voto>. Acesso em: 05 ago. 2014.

PEREIRA, Elvis. A Bolívia é aqui. Revista são paulo, São Paulo, n. 151, p. 32-38, 2013.

RIBEIRO, Darcy. As Américas e a civilização: formação histórica e causas do desenvolvimento desigual dos povos americanos. 5. ed. Petrópolis, RJ: Vozes, 1988.

RODRIGO ALSINA, Miquel. Elementos para una comunicación intercultural. Afers Internationals, Cidob, Barcelona, n. 36, p. 11-21, 1997. Disponível em: <http://www.cidob.org/es/content/download/5783/55624/file/36rodrigo_cast.pdf>. Acesso em: 02 fev. 2014.

. ¿Por qué interculturalidad? Revista interacción, Santa Fé de Bogotá, n. 25, 2001. Disponível em: <http://interaccion. cedal.org.co/25/interculturalidad. htm>. Acesso em: 02 ago. 2014.

SILVA, Sidney Antônio da. Costurando sonhos. trajetória de um grupo de imigrantes bolivianos em São Paulo. São Paulo: Paulinas, 1997.

. Dinâmica cultural e processos identitários. In: BAENINGER, Rosana (Org.). Imigração boliviana no Brasil. Campinas: Núcleo de Estudos de População-Nepo/Unicamp; Fapesp; CNPq; Unfpa, 2012. p.19-74.

Artigo recebido em 20.08.2014 e aprovado em 25.09.2014. 